\title{
The Relationship between Treating, after Treated of Osteoarthritis, Osteoporosis and Quality of Life in Korean Adults: Based on the 2010 Korean Community Health Survey
}

\begin{abstract}
The purpose of this study was to investigate the relationship the quality of life, osteoarthritis and osteoporosis in the Republic of Korea. This study was utilized raw data from the $2010 \mathrm{KCHS}$. In total, 229,229 individuals participated in the 2010 survey. The final analysis was identified 22,545 individuals who had been diagnosed by a doctor with arthritis or osteoporosis. To identify the relationship between the quality of life - related after treated or treating of arthritis, osteoporosis, A multiple linear regression analysis was performed. Treating group for osteoarthritis of their quality of life has statistically been less than after treated group( $\mathrm{B}=-.068, \mathrm{p}$ (.001). Treating group for osteoporosis of their quality of life has statistically been less than after treated $\operatorname{group}(\mathrm{B}=-.083, \mathrm{p}\langle .001)$. Non-treatment group who was diagnosed by doctor, but no treated subject for osteoarthritis of their quality of life has statistically been less than after treated group(B=-.075, p<.001). Non-treatment group that was diagnosed by doctor, but no treated subject for osteoporosis of their quality of life has statistically been less than after treated group( $B=-.045, p<.001)$. Non-treatment group who was diagnosed by doctor, but no treated subject for osteoporosis and arthritis of their quality of life has statistically been less than after treated group( $B=-.0121$, $\mathrm{p}(.001)$. as a result of those data, we understand that the decision maker for treatment has been chosen by quality of life, including pain, mobility activity and so on.
\end{abstract}

Key words: Arthritis, Quality of life(QOL). Osteoporosis
Hyuk Jegal ${ }^{a}$, Hyun Ju Jun ${ }^{a}, \mathrm{Ki}$ Jong Kim

${ }^{a}$ Cheongam College, Suncheon, Korea

Received : 20 November 2014

Revised : 28 December 2014

Accepted : 27 January 2015

Address for correspondence

Ki Jong Kim, PT, Ph.D

Department of Physical Therapy, Cheongam College, 1641 Noksaek-ro,

Suncheon, Korea

Tel: 82-10-6888-3677

E-mail: kjparadise@hanmail.net

\section{INTRODUCTION}

According to the osteoarthritis(OA) research society international disease state working group, they were defined as OA is progressive disease representing the failed repair of joint damage that, in the preponderance of cases, has been triggered by abnormal intra-articular stress(1). $\mathrm{OA}$ is the most common form of arthritis, and is a major cause of morbidity, activity limitation, physical disability, excess health care utilization and reduced health-related Quality of life(QOL), especially in people aged 45 and above in developed countries(2). The world health organization's scientific group on rheumatic diseases estimates that $10 \%$ of the world's population aged 60 years or older has significant clinical problems that could be attributed to OA as well as the highest OA prevalence estimates are found in the hand joints, with woman commonly affected than men(3). OA is often characterized by pain, the common symptom for which people with OA seek treatment. Pain in OA affects the ability to engage in activities of daily living, work, and other meaningful activities and is associated with a reduced QOL(4-6).

The QOL refers to the physical, social domains and psychological of health seen as distinct areas that are influenced by a person's experiences, beliefs, perceptions(7).

In QOL, it used to measure health using three levels of severity in five dimensions such as mobility, self-care, usual activity, pain/discomfort, and anxiety/depression(8).

In aspect of treatment, recent guidelines from 
the American College of Rheumatology (ACR) strongly recommend weight loss for overweight patients with knee or hip OA, as well as cardiovascular and/or resistance land-based exercise and aquatic exercise(9). With OA, the world health organization has estimated that $30 \%$ of all women aged over 50(postmenopausal) have osteoporosis according to a definition of bone mineral density being more than 2.5 standard deviation below the mean for young healthy adult women at any site(10).. therefore many population has those disease and then should be guessed that the popluation can be affected for their quality of life by those disease in south korea

\section{METHODS}

\section{Subjects}

We utilized the original data which was gathered from Korea centers for disease and prevention for studying the relationship between QOL, osteoarthritis and osteoporosis. Researchers investigated a sample surveys from August 16 2010 to October 312010 in the selected house as a sample because the Korean Community Health Survey(KCHS) investigates research in which they select a sample to represent a population as national sampling research in annually. A sample was extracted a sample cooperated with the ministry of land, infrastructure and transportation which they provided the type of house and a number of house data as well as address of a house from the ministry of public administration and security. Based on those data, sampled 900 houses were extracted for investigating each community health center.

This research was performed the sampling investigation with collaboration from the nation's Korea center for disease control and prevention, 16 city and province, 253 community health center, 36 universities. The object of this investigation was 229,229 and 228,660 was extracted in this research, but 629 who were not clear of their diagnosis and data of QOL(11,12). The general characteristics of the subjects are presented in Table 1.

\section{Methods}

For QOL, the EQ-5D, an evaluation tool developed by the Euro-QoL Group founded in 1987, was used. The subjects were instructed to respond to five items on mobility, self-care, usual activity, pain/discomfort, and anxiety/depression and rate

Table 1. General characteristics of subjects.

\begin{tabular}{|c|c|c|c|c|c|c|c|}
\hline Characteristics & $\mathrm{n}$ & $\%$ & \%SE & Characteristics & $\mathrm{n}$ & $\%$ & $\% S E$ \\
\hline SEX & & & & Residential area & & & \\
\hline Men & 104,371 & 49.5 & .1 & Urban & 127,106 & 80.6 & .1 \\
\hline Woman & 124,229 & 50.5 & .1 & Rural & 101,494 & 19.4 & .1 \\
\hline Age(years) & & & & Living with family & & & \\
\hline $19-64$ & 174,711 & 86.2 & .1 & Yes & 205,009 & 91.9 & .1 \\
\hline $65-74$ & 34,695 & 9.2 & .1 & No(alone) & 23,591 & 8.1 & .1 \\
\hline$\geq 75$ & 19,194 & 4.6 & .0 & Treating for osteoporosis & & & \\
\hline Educational level & & & & No & 219,202 & 97.6 & .0 \\
\hline Elementary school level & 63,952 & 16.1 & .1 & Yes & 9,398 & 2.4 & .0 \\
\hline Middle school level & 25,943 & 9.3 & .1 & Treating for arthritis & & & \\
\hline High school level & 138,115 & 74.6 & .1 & No & 210,775 & 95.5 & .0 \\
\hline Monthly household income & & & & Yes & 17,825 & 4.5 & .0 \\
\hline (10,000won) & & & & Having or not bony disorder & & & \\
\hline$\leq 100$ & 56,486 & 17.5 & .1 & No & 206,055 & 94.1 & .1 \\
\hline $101-200$ & 47,109 & 22.0 & .2 & Only osteoporosis & 4,720 & 1.4 & .0 \\
\hline $201-300$ & 42,372 & 22.9 & .2 & Only osteoarthritis & 13,147 & 3.4 & .0 \\
\hline $301 \leq$ & 62,176 & 37.6 & .2 & Both of them & 4,678 & 1.1 & .0 \\
\hline
\end{tabular}

* $\mathrm{N}$ : sample size. †\%: estimated percent of the population 
the items as not a problem, a minor problem, or a serious problem using a 3 -point Likert scale. The EQ-5D was calculated using the following equation. In order to know correlation subject who has osteoarthritis or osteoporosis or both of them and their QOL,

$$
\begin{aligned}
& \mathrm{EQ}-5 \mathrm{D}=1-(.05+.096 \times \mathrm{M} 2+.418 \times \mathrm{M} 3+ \\
& .046 \times \mathrm{SC} 2+.136 \times \mathrm{SC} 3+.051 \times \mathrm{UA} 2+.208 \times \\
& \mathrm{UA} 3+.037 \times \mathrm{PD} 2+.151 \times \mathrm{PD} 3+.043 \times \mathrm{AD} 2 \\
& +.158 \times \mathrm{AD} 3+.05 \times \mathrm{N} 3)
\end{aligned}
$$

\section{Data analysis}

The collected data were analyzed using IBM SPSS Statistics 21.0 and a complex sampling design. Individual weights were applied in order to estimate a population. A frequency analysis was performed to examine the distribution of subjects. To identify the correlation between the aftereffect-related characteristics of osteoarthritis, osteoporosis patients and QOL, a multiple linear regression analysis was performed controlling for gender, age, education level, marital status, monthly household income, residential area, physical activity, and presence of venereal diseases. The presented data used relative frequencies $(\%)$ and standard errors estimated by applying weighted values, cross ratios, and a 95\% confidence interval. The statistical significance level for statistical testing was $\alpha=.05$.

\section{RESULTS}

To investigate the relationship between the OA, osteoporosis and QOL, a multiple linear regression analysis was performed, adjusting their characteristics such as their gender, educational level, and so on.

Treating group for OA of their QOL has statistically been less than after treated group $(B=-.068$, $\mathrm{p}<.001)$, treating group for osteoporosis of their QOL has statistically been less than after treated group $(B=-.083, p<.001)$. Non-treatment group that was diagnosed by doctor, but no treated subject for OA of their QOL has statistically been less than after treated group $(B=-.075, p<.001)$. Nontreatment group who was diagnosed by doctor, but no treated subject for osteoporosis of their QOL has statistically been less than after treated group $(\mathrm{B}=-.045, \mathrm{p}<.001)$. Non-treatment group that was diagnosed by doctor, but no treated subject for osteoporosis and arthritis of their QOL has statistically been less than after treated $\operatorname{group}(\mathrm{B}=-.0121, \mathrm{p}<.001)$.

\section{DISCUSSION}

$\mathrm{OA}$ is an extremely common condition after 40 years of age, although it may not always be symptomatic when present. It is widespread in adults over 60 , and affects men more than women(13). There are two kinds of categories in the treatment of OA. One is the pharmacologic approach such as symptomatic and slow acting symptomatic drugs.

Unlike a pharmacologic approach which has adverse effects, Non-pharmacologic approach, which strengthening exercise(14), water based exercises(15) has been reported to reduce pain and disability through. As well as stretching also benefits to

Table 2. Results of multiple regression analysis for QOL

\begin{tabular}{cccccc}
\hline & R2 & B & SE & $t$ & $P$ \\
\hline $\begin{array}{c}\text { Treating osteoporosis/No) } \\
\text { Yes }\end{array}$ & .229 & -.068 & .003 & -24.301 & $.001^{* *}$ \\
$\begin{array}{c}\text { Treating osteoarthritis/No) } \\
\text { Yes }\end{array}$ & & -.083 & .002 & -41.693 & $.001^{* *}$ \\
Bony disorder/No) & .246 & & & & \\
Only osteoporosis & & -.045 & .003 & -14.220 & $.001^{* *}$ \\
Only osteoarthritis & .251 & -.075 & .002 & -36.610 & $.001^{* *}$ \\
Both of them & & -.121 & .004 & -26.921 & $.001^{* *}$ \\
\hline
\end{tabular}

* Adjust for sex, age, educational level, monthly household income, resdential area, living witj family 
The Relationship between Treating, after Treated of Osteoarthritis, Osteoporosis and Quality of Life in Korean Adults: Based on the 2010 Korean Community Health Survey

relief pain and gait speed in $\mathrm{OA}(16)$

Osteoporosis is a common disease that manifests itself as fractures occurring at multiple skeletal sites, most often at the spine, hip or wrist and causes significant morbidity and mortality(17).

Osteoporotic fractures are a major cause of morbidity in the population. Specific fractural sites such as hip fracture cause acute pain and loss of function, and nearly always lead to hospitalization(18).

To prevent falling down, the participant can be trained their empowerment and self-efficacy, resumed activities and became more active after participation in balance training programs with osteoporosis(19). QOL is a useful and widely-used of health status because it captures to personal and social context of patient's lives in the quantifiable way, and predicts a use of health care resources and mortality $(20,21)$.

In case of a knee OA, it is associated with symptoms of pain and functional disability. Physical disability arising from pain and loss of functional capacity reduces QOL and increases the risk of further mortality and morbidity(22).

In case of osteoporosis, many of the patients can complain in their back pain and as a result; it has the relationship between spinal deformation and QOL components(23). Therefore, the QOL can be influenced by OA and osteoporosis. The results of this study also showed that the subjects who had a osteoarthritis and osteoporosis appeared lower QOL on their survey.

It especially subjects who has been received a treatment had lower QOL rather than treated subject. The QOL, including pain/discomfort, mobility, etc., it can be a decision making to receiving treatment or not on $\mathrm{OA}$, osteoporosis.

Among the limitations of this study, data accuracy and could not be maximized through data segmentation because KCHS data were used instead of data collected exclusively for the purposes of analyzing QOL and OA and osteoporosis. However, this study utilized highly valuable data that can be generalized as nationwide data. Follow-up studies conducted with higher levels of data segmentation is likely to produce higherquality results.

\section{CONCLUSION}

These results can be some evidence which people can participate a treatment osteoarthiritis and osteporosis can affect people's QOL, and then most of population treats their disease to change of QOL. Many of them treat for their disease because their QOL still does not change. therefore QOL is one of decision maker to treat those disease and the purpose of treatment is to change of their QOL.

\section{REFERENCES}

1. Lane N, Brandt K, Hawker G, E Peeva, E Schreyer, W, Tsuji, C, Hochberg. OARSI-FDA initiative: defining the disease state of osteoarthritis. Osteoarthritis and Cartilage, 2011; 19: 478-482.

2. Lawrence RC, Felson DT, Helmick CG, Arnold LM, Hyon Choi, Deyo RA, Sherine Gabriel, Rosemarie Hirsch, Hochberg MC, Hunder GG, Jordan JM, Katz JN, Hilal MK, Frederich W. Estimates of the prevalence of arthritis and other rheumatic conditions in the United States: Part II. Arthritis \& Rheumatism, 2008; 58: 26-35.

3. Cooper C, Dennison E, Edwards M, Anna L. Epidemiology of osteoarthritis. Medicographia, 2013; 35: 145-151.

4. Hill C, Parsons J, Taylor A, Leach G. Health related quality of life in a population sample with arthritis. The Journal of rheumatology, 1999; 26: 2029-2035.

5. Grotle M, Hagen KB, Natvig B, Fredrik AD, Tore KK. Prevalence and burden of osteoarthritis: results from a population survey in Norway. The Journal of rheumatology, 2008; 35: 677-684.

6. Boutron I, Rannou F, Jardinaud-Lopez M, Meric G, Revel M, Poiraudeau. Disability and quality of life of patients with knee or hip osteoarthritis in the primary care setting and factors associated with general practitioners' indication for prosthetic replacement within 1 year. Osteoarthritis and Cartilage, 2008; 16: 1024-1031.

7. Patrick DL, Bush J,Chen MM. Toward an operational definition of health. Journal of Health and Social Behavior, 1973; 6-23.

8. Herdman M, Gudex C, Lloyd A, Janssen MF, Kind P, Parkin D, Bonsel G, Badia X. Development and preliminary testing of the new five-level version of $\mathrm{EQ}-5 \mathrm{D}$ ( $\mathrm{EQ}-5 \mathrm{D}-5 \mathrm{~L})$. Quality of life research, 2011; 20: 1727-1736.

9. Hochberg MC, Altman RD, April KT, Maria N, Gordon G, Jessie MG, Tanveer T, Vivian W, George 
W, Peter T. American College of Rheumatology 2012 recommendations for the use of nonpharmacologic and pharmacologic therapies in osteoarthritis of the hand, hip, and knee. Arthritis care \& research, 2012; 64: 465-474.

10. World Health organization. Assessment of fracture risk and its application to screening for postmenopausal osteoporosis: report of a WHO study group [meeting held in Rome from 22 to 25 June 1992]. 1994.

11. Kim YT, Choi BY, Lee KO, et al. Overview of Korean community health survey. Journal of the Korean Medical Association, 2012; 55: 74-83.

12. Oh DH, Kim SA, Lee HY, Seo JY, Choi BY, Nam JH. Prevalence and correlates of depressive symptoms in Korean adults: results of a 2009 Korean community health survey. Journal of Korean medical science, 2013; 28: 128-135.

13. Moskowitz R, Howell D, Goldberg V. Osteoarthritis-symptoms and signs. Osteoarthritis Diagnosis and medical/surgical management Moskowita RW, Howell DS, Goldberg VM, Mankin HJ Philadelphia: WB Saunders Company, 1992; 255-261.

14. Gro J, Kristin TD, Anne C, Rikke HM, Espen H, Inger $\mathrm{H}$, Kåre BH. Physical therapy interventions for patients with osteoarthritis of the knee: an overview of systematic reviews. Physical therapy, 2007.

15. Bartels EM, Lund H, Hagen KB, Dagfinrud H, Christensen R, Danneskiold-Sams øe B. Aquatic exercise for the treatment of knee and hip osteoarthritis. The Cochrane Library, 2007.

16. Aoki O, Tsumura N, Kimura A, Okuyama S, Takikawa S, Hirata S. Home stretching exercise is effective for improving knee range of motion and gait in patients with knee osteoarthritis. Journal of Physical Therapy Science, 2009; 21: 113-119.
17. Barrett-Connor E. The economic and human costs ofosteoporotic fracture. The American journal of medicine, 1995; 98: 3S-8S.

18. Kanis JA, Burlet N, Cooper C. Delmas PD, Reginster JY, Borgstrom F, Rizzoli R. European guidance for the diagnosis and management of osteoporosis in postmenopausal women. Osteoporosis International, 2013; 24: 23-57.

19. Halvarsson A. Fall-related concerns, balance and gait in older adults with osteoporosis. 2015.

20. David AD, Spencer SJ, Laurie B, Steven M. Donnelly, Cherie P, Brunker, AdamWilcox, Paul D. Clayton. Use of Health-Related, Quality of Life Metrics to Predict Mortality and Hospitalizations in Community-Dwelling Seniors. Journal of the American Geriatrics Society, 2006; 54: 667-673. Singh JA, Nelson DB, Fink HA, Nichol KL.

21. Health-related quality of life predicts future health care utilization and mortality in veterans with self-reported physician-diagnosed arthritis: the veterans arthritis quality of life study. Seminars in arthritis and rheumatism: Elsevier 2005; 755-765.

22. Jordan KM, Arden NK, Doherty M, et al. EULAR Recommendations 2003: an evidence based approach to the management of knee osteoarthritis: Report of a Task Force of the Standing Committee for International Clinical Studies Including Therapeutic Trials (ESCISIT). Annals of the rheumatic diseases, 2003; 62: 1145-1155.

23. Leidig-BG, Minne H, Schlaich C, Wagner G, Scheidt NC, Burckner T, Gebest HJ, Ziegler R. Clinical grading of spinal osteoporosis: quality of life components and spinal deformity in women with chronic low back pain and women with vertebral osteoporosis. Journal of Bone and Mineral Research, 1997; 12: 663-675. 